\title{
“Hacia una idea de justicia en el horizonte de una sociedad superior en la filosofía de Friedrich Nietzsche"
}

\author{
García Barros, María Cielo \\ Universidad Nacional del Nordeste
}

\section{Resumen}

En este artículo se abordará la relación existente entre el concepto de "justicia" y las características de la nueva y superior sociedad propuesta por el filósofo Friedrich Nietzsche. Se entiende aquí a la justicia como el sentido contingente que adquieren las normas jurídicas en cada época y lugar a partir de un determinado conjunto de valores. La justicia será entonces el resultado de un consenso entre los individuos de una sociedad sobre lo considerado "bueno" y "malo", y sobre cómo han de organizar sus relaciones.

Es por ello que se considera necesario problematizar en primera instancia si es que Nietzsche propone, en el seno de esta nueva sociedad, el ejercicio de una "moral superior" o por el contrario, de una especie de "ethos" alternativo. Su crítica profunda al contenido de la tradición judeo-cristiana y su concepción perspectivista de la verdad nos hace deducir la imposibilidad de la continuidad de cualquier tipo de moral, pero a su vez pareciera ser que el filósofo sigue argumentando dentro de este universo.

Palabras clave: moral, ethos, justicia, sociedad superior, expansión vital.

\section{Abstract}

This article will address the relationship between the concept of "justice" and the characteristics of the new and superior society proposed by the philosopher Friedrich Nietzsche. Justice is understood here as the contingent sense acquired by legal rules in each time and place from a set of values. Justice will then be the result of a consensus among the individuals of a society about what is considered "good" and "bad", and how they are to organize their relationships. 
That is why it is considered necessary to problematize in the first instance if Nietzsche proposes, within this new society, the exercise of a "superior morality" or, on the contrary, a kind of alternative ethos. His deep criticism of the content of the JudeoChristian tradition and his perspectivist conception of truth makes us deduce the impossibility of the continuity of any type of morality, but in turn it seems that the philosopher continues to argue within this universe.

\section{Introducción}

El tema del presente trabajo de investigación se presenta dentro del área ética de la filosofía de Friedrich Nietzsche así como también se ve vinculado con una posible filosofía del derecho todavía embrionaria en su pensamiento.

El tema pues que se ha elegido para investigar es la relación existente entre el concepto de "justicia" y las características de la nueva y superior sociedad propuesta por el filósofo, en donde el protagonista de ella es el superhombre y su capacidad creadora de valores.

Dos preguntas guían el trabajo: ¿es posible pensar la continuidad de una "moral" en el seno de la sociedad superior propuesta por Niezsche? y por otra parte ¿cuál será el nuevo modo de concebir a la justicia y de qué modo actuará ésta en el marco de una sociedad superior?

La justicia actualmente se entiende tanto como "ideal", como aquella "voluntad de respetar y honrar" lo que se encuentra plasmado en el derecho positivo, el cual a su vez se entiende como la materialización parcial o total (según cada doctrina) de aquel ideal. El derecho positivo, a su vez, es el ordenamiento jurídico (conjunto de normas jerárquicamente establecidas) que una sociedad establece en cada época y lugar y va modificando. En ambas definiciones se observa que la justicia es un "sentido" sobre las normas jurídicas, el cual varía según cada sociedad. Este sentido, se configurará a partir de un determinado conjunto de valores que posea la 
sociedad a la que la justicia sirva de parámetro, es decir, a partir de su moral. Una concepción de justicia es, en definitiva, el resultado de un consenso entre los individuos de una sociedad sobre lo considerado "bueno" y "malo", y sobre cómo han de organizarse las relaciones entre estos.

Se planteó como hipótesis y posteriormente se confirmó la siguiente idea: lo que determina el concepto de justicia nietzscheana una vez despojado éste de todo sentimiento reactivo-vengativo, sigue siendo una "moral" aunque construida a partir de un fin radicalmente diferente a la anterior: la expansión vital. La justicia se constituye como un concepto activo, que busca el desarrollo de hombres superiores. El hombre "justo" actuará de manera objetiva, incluso con aquel que lo ha perjudicado y se someterá también a las leyes que prescriba, aunque, como se ha dicho, siempre con miras al fin teleológico establecido antes.

El objetivo principal del trabajo y a su vez el motor de la investigación es la necesidad de explicitar y profundizar lo mayor posible su concepción de justicia, en tanto que éste resulta ser un eslabón de su pensamiento poco explorado en comparación con sus estudios genealógicos de la moral.

Con este fin, se considera pertinente para el abordaje tanto del campo, como del objeto y así también de la problemática planteada, el método analíticocomparativo y comprensivo, el cual consistirá en separar en partes mínimas los componentes de cada concepto para así observar los matices de cada uno de ellos, y luego compararlos entre sí haciendo satisfactoria la comprensión.

\section{CAPÍTULO PRIMERO: “Ideas nietzscheanas sobre occidente y su tradición: moral y} justicia"

\subsection{Caracterización de la moral occidental}


"El concepto de bueno y malo tiene una doble prehistoria"171 comienza diciendo Nietzsche. $\mathrm{Y}$ aquí, de principio, el hecho de que se sostenga sobre estos conceptos que tienen una historia en general, significa nada más y nada menos que no son ni eternos ni universales ni inmutables, como más adelante se verá, la religión cristiana pretendió disfrazar. Que estén inmersos en la historia, en el devenir, supone un apego a lo terrenal, a lo mundano, a lo azaroso, al hombre y sus instintos.

\subsubsection{Prehistoria moral}

En un primer momento, fueron los hombres aristócratas y poderosos quienes, por un movimiento espontáneo, se autodeterminaron "buenos", debido a sus particulares características: alta jerarquía económica y una disposición anímica marcada por la veracidad. Constituyendo una comunidad unificada por el sentimiento común de la revancha. El enemigo no es visto por este grupo de hombres en términos de maldad, ya que puede pagar con la misma moneda.

Sin embargo, en contraste con estos, se encontraba aquel grupo de hombres más bien similar a una "masa" sin lazos de unidad, que se presentaba a los ojos de los aristócratas como plebeyos, débiles y mentirosos, los propiamente llamados "malos" pero solo en sentido de "despreciables" ${ }^{172}$. Nietzsche sostiene esta idea presentando una indagación sobre la etimología de las palabras "bueno" y "malo" en distintas lenguas. Precisamente en el mismo idioma del filósofo, la palabra que designa lo malo "schlechz" comparte similitud con "schlicht" lo simple o vulgar.

\footnotetext{
${ }^{171}$ NIETZSCHE, Friedrich. Humano, demasiado humano. Un libro para espíritus libres. Primer volumen. Trad. Alfredo Brotons Muñoz. Madrid, Akal, 2007. p. 70.

172 'En el primer caso, cuando los dominadores son quienes definen el concepto de 'bueno', son los estados psíquicos elevados y orgullosos los que son sentidos como aquello que distingue y que determina la jerarquía. El hombre aristocrático separa de sí a aquellos seres en los que se expresa lo contrario de tales estados elevados y orgullosos: desprecia a esos seres. Obsérvese enseguida que en esta primera especie de moral la antítesis 'bueno' y 'malo' es sinónima de 'aristocrático' y 'despreciable'". NIETZSCHE, Friedrich. Más allá del bien y el mal. Preludio de una filosofía del futuro. Trad. Andrés Sánchez Pascual. Alianza, Madrid, 2001. p. 236.
} 
Nietzsche explica esta auto-segregación originaria con el concepto de "pathos de distancia" el cual se define como un "sentimiento global y radical de una especie superior dominadora en su relación con una especie inferior"173. Los "buenos" a partir de aquí se adjudicaron el derecho de crear valores conforme a sus cualidades.

\subsubsection{Sociedad judía: nacimiento de la moral del ressentiment}

En tanto que la casta sacerdotal va adquiriendo mayor poder e influencia en el seno ya de la sociedad judía, Nietzsche percibe el comienzo de un movimiento particular de transvaloración ejecutado a partir del sentimiento de impotencia. Los sacerdotes experimentan recelo hacia la aristocracia caballeresco-guerrera predominante en ese tiempo, pero se descubren a la vez débiles frente a estos, incapaces de llevar a cabo sus deseos. Nietzsche plantea que tanto la discapacidad y el sentimiento de impotencia generan en aquellos una "dolencia crónica" que pasa a envenenar tanto el cuerpo como el alma ${ }^{174}$. Más adelante se verá como este "veneno" contamina todo aquello que en adelante hereda algo de esta tradición.

La manera en la cual ejecutan esta venganza resulta ser una inversión de los valores aristocráticos. Esta inversión representa el segundo momento en la prehistoria de los términos bueno y malo.

¡los miserables son los buenos; los pobres, los impotentes, los bajos son los únicos buenos; los que sufren, los indigentes, los enfermos, los deformes son también los únicos piadosos, los únicos benditos de Dios, únicamente para ellos existe bienaventuranza, en cambio vosotros, vosotros los nobles y violentos, vosotros sois, por toda la eternidad, los malvados, los crueles, los lascivos, los insaciables, los ateos, y vosotros seréis

\footnotetext{
${ }^{173}$ NIETZSCHE, Friedrich. La genealogía de la moral. Trad. Andrés Sánchez Pascual, Alianza, Bs. As., 2008. p.39.

${ }^{174}$ Cfr. NIETZSCHE, Friedrich. Humano, demasiado humano. Un libro para espíritus libres. Primer volumen. Op. Cit., p. 77.
} 
también eternamente los desventurados, los malditos y condenados! ${ }^{175}$

En esta cita resume Nietzsche la inversión de planos ejecutada por la casta sacerdotal. Si los aristócratas anteriormente estimaban su poderío económico, ahora los mendigos y hambrientos verán glorificada su carencia, al igual que los enfermos sus defectos biológicos y los cobardes su incapacidad de acción. La moral de esclavos no tiene su origen en el mundo supraterrenal, sino que entre otras cosas se relaciona con la mundana utilidad, una manera de hacer la vida de los débiles, más soportable ${ }^{176}$.

Pero he aquí la astucia de los sacerdotes, los aristócratas no serán considerados sólo "malos" en sentido de menosprecio, sino "malvados" (böse) denominación que aumenta el estigma porque supone que éstos son libres de actuar de tal o cual manera y cada vez que lo hacen, deciden con crueldad llevarlo a cabo.

No es de menor importancia tampoco en la filosofía de Nietzsche, el hecho de que la voluntad de modificar valores en los sacerdotes haya nacido del resentimiento y el odio. Nietzsche considera que los sentimientos reactivos, nacen de aquellos a quienes "les está vedada la auténtica reacción" 177 la cual consistiría en actuar siempre a partir de sí. En cambio, aquellos se limitan a un movimiento de negación hacia lo otro, y hacia lo que se encuentra afuera. "Para surgir, la moral de los esclavos necesita siempre primero un mundo opuesto y externo, necesita, hablando fisiológicamente, de estímulos exteriores para poder en absoluto actuar, -su acción es, de raíz, reacción"178. En tanto los sentimientos "activos" poseen mayor autenticidad por emerger desde el

\footnotetext{
${ }^{175}$ NIETZSCHE, Friedrich. La genealogía de la moral. Op. Cit., p. 46.

176 “(...) es la compasión, la mano afable y socorredora, el corazón cálido, la paciencia, la diligencia, la humildad, la amabilidad lo que aquí se honra, pues estas propiedades son aquí las más útiles y casi los únicos medios para soportar la presión de la existencia." NIETZSCHE, Friedrich. Más allá del bien y el mal. Preludio de una filosofía del futuro. Op. Cit., p. 239.

177 Ibíd. p. 49.

${ }^{178}$ Ibíd. p. 50.
} 
mismo ser, los reactivos en cambio dan lugar a construcciones artificiosas e inauténticas.

\subsubsection{Cristianismo e invención de la culpa}

Enseguida, el cristianismo, la religión que nace del pueblo judío, toma esta pesada herencia: el prejuicio metafísico de la cosa en sí y la separación de los mundos platónica, el odio y el resentimiento judío y sus valores negadores de la vida y construye sobre ella su identidad. El producto acabado de esta profundización de la tradición es la moral de esclavos y la consolidación del hombre gregario ${ }^{179}$.

Los eternos "siervos" construyen una moral que haga más llevadera su condición de esclavos. Como observan que no pueden más que obedecer a los señores, los siervos establecen que la obediencia es buena y que el orgullo es malo. Como los esclavos son débiles, promueven valores como la mansedumbre, la misericordia y la compasión, por el contrario, critican el egoísmo, la fuerza y venganza. Como son pobres, promueven la humildad y despojo.

También, en tanto que resienten de todo lo superior y lo noble, de la diferencia y la jerarquía, éstas serán características denunciadas en pos de la defensa vigorosa de una igualdad mediocre entre todos los hombres en tanto hermanos del Dios padre, y en tanto juzgables ante los ojos de un Dios juez. Esta idea, aunque laicizada será recuperada como estandarte en la modernidad por la llustración. Lo importante aquí es identificar que la voluntad de igualdad nace como el resto de los valores judíos, de la raíz del resentimiento.

\footnotetext{
${ }^{179}$ El hombre gregario se caracteriza por asumir posiciones por "habituación", optar por lo corriente, en este caso, un conjunto de principios valorativos, ideales de acción, que constituyen la tendencia hegemónica de ese tiempo y lugar. La permanencia en el gregarismo de las opiniones conduce en el hombre al fortalecimiento del carácter, ya que los pocos motivos que le brinda su limitado intelecto y entre los que decide su acción, le permiten agilizar el proceso de elección y volcar toda la energía a la ejecución de la acción.
} 
Por otra parte, con el cristianismo se presenta además una de las ideas "más enfermizas" de nuestra cultura, la idea de culpabilidad. La interiorización de la culpa principalmente en el seno de los hombres fuertes, constituirá el triunfo de la venganza de los hombres resentidos. Nietzsche explica el proceso comenzando por el desarrollo de la conciencia: ésta va prosperando a lo largo de toda la prehistoria, mediante la acción de la sociedad y la eticidad de la costumbre, las cuales se encargan de hacer al hombre uniforme y calculable, es decir responsable y capaz de prometer a los efectos de la vida en comunidad. La mala conciencia, o conciencia de culpa es el producto de la vuelta hacia dentro de los instintos, es el "instinto de la libertad reprimido, retirado, encarcelado en lo interior y que acaba por descargarse y desahogarse tan sólo contra sí mismo"180 " "Todo el mundo interior, originariamente delgado, como encerrado entre dos pieles, fue separándose y creciendo, fue adquiriendo profundidad, anchura, altura, en la medida en que el desahogo del hombre hacia fuera fue quedando inhibido" ${ }^{181}$.

Nietzsche se pregunta: “¿se han imaginado, aunque sólo sea de lejos, que, por ejemplo, el capital concepto moral 'culpa' (Schuld) procede del muy material concepto 'tener deudas' (Schulden) ${ }^{182}$ A partir de esta introducción comenzará a desenvolver el camino que recorrió la culpa en la vida del hombre hasta los tiempos del cristianismo.

Al principio, la relación de deuda se desarrollaba en un plano personal, entre acreedores y deudores, entre quienes tenían poderío económico y fuerza y quienes no. La aplicación de la pena al deudor intentaba establecer una equivalencia entre el castigo (dolor) y el perjuicio al acreedor, el cual generaba en este último un cierto goce. En este estadio, todavía el penado, el deudor, no se siente en sí "culpable" o con remordimiento por la trasgresión, por el contrario, Nietzsche afirma que se entiende inmerso en una situación azarosa, accidental, y, además "la pena endurece y vuelve frío, concentra, exacerba el sentimiento de extrañeza, robustece la fuerza de

\footnotetext{
${ }^{180}$ NIETZSCHE, Friedrich. La genealogía de la moral. Op. Cit., p. 112.

${ }^{181}$ Ibíd. p. 109.

${ }^{182}$ Ibíd. p. 82.
} 
resistencia” ${ }^{183}$. Vemos que en el estadio de la culpa material solamente hay un efecto de temor de ser dañado, de ser castigado por el acreedor, así el deudor busca simplemente evitar la agresividad morbosa del acreedor ante el incumplimiento de la deuda. No hay todavía interiorización.

En tanto el proceso de civilización avanza, la relación de deuda se desliza hacia un plano mayor: la sociedad o comunidad entera serán acreedoras de paz y confort y el individuo será el deudor. En la medida en que crece el poder de la comunidad, la deuda también crece y se vuelve impagable. $Y$, de alguna manera, sostiene Nietzsche, los hombres interpretan que pueden saldar una parte de su deuda otorgando mayor poder a un dios, es así como nace el Dios cristiano, el más poderoso de la historia.

$$
\begin{aligned}
& \text { Una deuda con Dios: este pensamiento se le convierte en } \\
& \text { instrumento de tortura. Capta en 'Dios' las últimas antítesis que es } \\
& \text { capaz de encontrar para sus auténticos e insuprimibles instintos } \\
& \text { de animal, reinterpreta esos mismos instintos animales como } \\
& \text { deuda con Dios (como enemistad, rebelión, insurrección contra el } \\
& \text { 'Señor', el 'Padre', el progenitor y comienzo del mundo) }{ }^{184} \text {. }
\end{aligned}
$$

En estas líneas describe Nietzsche lo que el cristianismo llamara "pecado": los instintos del hombre, entendidos por este mismo como perjurio, culpa, deuda con Dios.

En resumen, la moral de esclavos, configura un medio completamente árido para el florecimiento de los hombres superiores quienes ven ahogadas y a la vez amenazadas sus potencialidades.

\subsubsection{Sociedad moderna defensora de la igualdad}

La modernidad ve florecer la democracia, Nietzsche sostendrá que ésta es la manifestación de la moral de esclavos en el ámbito político. Como bien se ha

\footnotetext{
${ }^{183}$ Ibíd. p. 105.

${ }^{184}$ Ibíd. p. 119.
} 
mencionado, la idea de igualdad entre los hombres, uno de los estandartes de la democracia, ha nacido en el seno de la sociedad judía.

En Así habló Zaratustra ${ }^{185}$, Nietzsche asemeja a los sacerdotes, ejecutores de la rebelión de los esclavos y la consecuente trasmutación de valores aristocráticos, a las tarántulas. Estos animales se caracterizan por poseer un veneno poderoso y transmitirlo con su mordedura. En el sacerdote, el veneno será su venganza y el efecto de éste, un trastorno de las almas. El personaje Zaratustra mueve con su dedo las redes tejidas por estas tarántulas a fin de que salgan a la luz sus mentiras, principalmente una: que "detrás de vuestra palabra 'justicia' se precipite vuestra

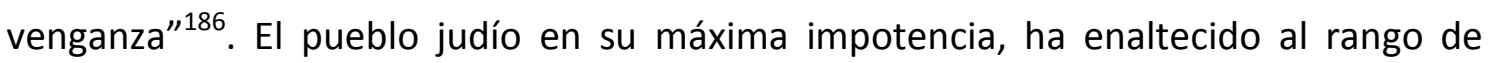
"virtud" la voluntad de igualdad, y empapado al concepto de justicia con ella. En este sentido, Nietzsche sostiene que la justicia entendida como igualdad, supone la ejecución de la más atroz venganza que pueda ser llevada a cabo en tanto que no solo beneficia a los inferiores y débiles sino que perjudica a sus enemigos, aquellos que tienen mayor poder y vigorosidad. Las tarántulas claman: “Nos vengaremos y difamaremos a todo el que no sea como nosotros" ${ }^{187}$. El veneno de los sacerdotes se ha impregnado y en la plaza pública, Zaratustra escucha a la plebe repetir "todos somos iguales, hombre es hombre; iante Dios todos somos iguales!"188.

Pero este veneno no solo se esparce en los márgenes del tiempo histórico propio de los sacerdotes, sino que, como se ha dicho, se propaga más tardíamente y llega hasta la contemporaneidad de Nietzsche. Éste experimenta en su tiempo, los efectos de las ideas del movimiento cultural de la Ilustración. En Crepúsculo de los Ídolos escribe sobre la Revolución Francesa: "(...) las tales llamadas "verdades" de la

\footnotetext{
${ }^{185}$ NIETZSCHE, Friedrich. Así habló Zaratustra. Trad. Andrés Sánchez Pascual, Alianza, Madrid, 1980.

${ }^{186}$ Ibíd. p. 105.

${ }^{187}$ Ibíd. p. 106.

${ }^{188}$ Ibíd.p. 256.
} 
revolución que todavía impactan y convencen todo lo que es llano y mediocre. ¡La doctrina de la igualdad!...Pero no hay veneno más venenoso: porque parece predicado de la justicia misma mientras que en verdad significa el fin de la justicia.... ${ }^{189}$. Particularmente, el ideal del contrato social pensado por Rousseau, pretende abolir la relación vertical en la que todo hombre es señor o esclavo y sustituir la obediencia del hombre hacia el hombre (uno más fuerte) por la obediencia de los hombres a la ley, la cual sería la expresión de la "voluntad general". La voluntad general, de la mayoría, engloba en una palabra la palabra de todos, difumina las opiniones disidentes en pos de una fuerza colectiva legisladora.

Pero la idea de "igualdad" de derechos no solo se pretenderá aplicar en el plano político sino también en distintas áreas de interés social: educación de masas, salud, trabajo emancipado, arte, en general: cultura cosmopolita. Una voluntad de nivelar al hombre en todos los planos de su vida con la excusa de universalizar el bienestar. Y agrega en la Gaya Ciencia:

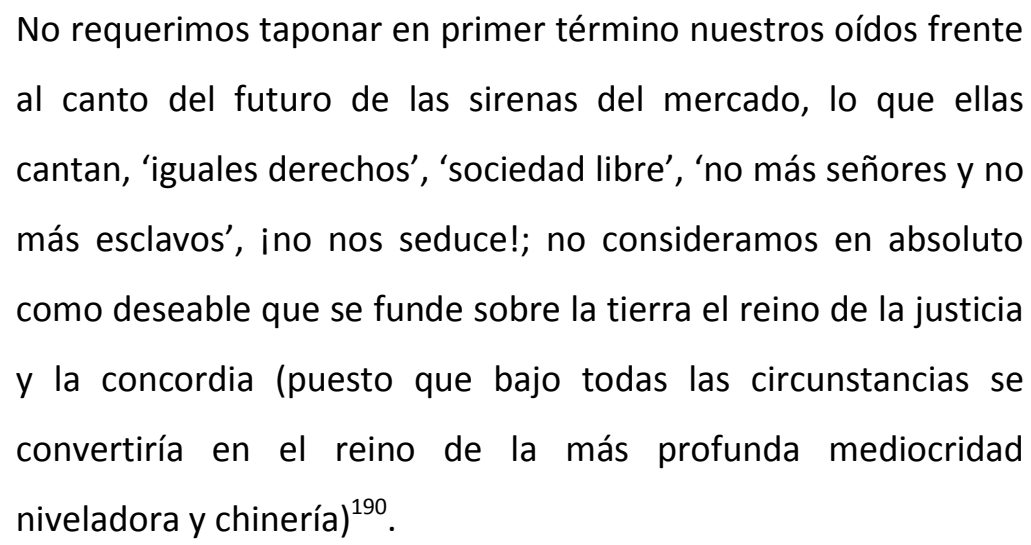

Dos ideas similares se extraen de estos fragmentos. Asumir como valor principal de la justicia la búsqueda de la igualdad conlleva el peligro de universalizar la mediocridad en el hombre, anular sus fuerzas, quitarle lo que tiene de particular a la

\footnotetext{
${ }^{189}$ NIETZSCHE, Friedrich. Crepúsculo de los ídolos, o Cómo se filosofa con el martillo. Trad. Andrés Sánchez Pascual. Alianza, Madrid, 2002. p. 155.

${ }^{190}$ NIETZSCHE, Friedrich. La ciencia jovial. Trad. José Jara, Monte Ávila, Venezuela, 1999. p. 249.
} 
vida, la cual no es más que "apropiación, ofensa, avasallamiento, de lo que es extraño y más débil, opresión, dureza, imposición de formas propias, anexión, y al menos, en el mínimum, explotación"191. Por esto se atreve a decir Nietzsche que sostener la igualdad, es la mayor de las injusticias cometidas contra el hombre, el fin de toda justicia.

\subsection{Concepción de "justicia” producto de la sociedad occidental}

A fin de caracterizar más acabadamente la concepción de justicia que resurge como el producto del desarrollo de la sociedad occidental, conviene recoger a fin de contrastarlas, las características dadas por Nietzsche del ejercicio de la justicia en la época prehistórica de la humanidad.

En la época prehistórica de la humanidad, la justicia no está determinada en su dimensión punitiva, sino retributiva. Los hombres plebeyos, a los que la capacidad de prometer y cumplir sus promesas les está vedada, incurren en faltas constantemente y son castigados por ello. Pero la conciencia de culpa como se ha dicho no había madurado todavía asi que éstos entendían sus actos como el producto del azar, así como también cuando sobrevenía el castigo, no lo asimilaba con remordimiento, sino como se entrega cualquiera a un evento más ${ }^{192}$.

Nietzsche observa que la retribución del perjuicio hacia los aristócratas, los únicos capaces de ocupar el lugar de acreedores, si bien comienza siendo material (los plebeyos deudores ofrecían a sus mujeres, su libertad, y hasta su cuerpo) evoluciona y "avanza" hacia una dimensión inmaterial: el placer de "hacer daño" a los deudores, en

${ }^{191}$ NIETZSCHE, Friedrich. Más allá del bien y el mal. Preludio de una filosofía del futuro. Op. Cit. p. 259.

192 “....de hecho durante larguísimo tiempo no apareció (...) nada referente a que aquí se tratase de un 'culpable'. Sino de un autor de daños, de un irresponsable fragmento de fatalidad. $Y$ aquel mismo sobre el que caía luego la pena, como un fragmento también de fatalidad, no sentía en ello ninguna 'aflicción interna' distinta de la que se siente cuando, de improviso, sobreviene algo no calculado. NIETZSCHE, Friedrich. La genealogía de la moral. Op. Cit., p. 106. 
tanto que este representa el ejercicio pleno de la distancia. Entre hombres de igual poder en cambio, la justicia consistirá en "ponerse de acuerdo entre sí, de volver a “entenderse" mediante un compromiso" ${ }^{193}$ volver a prometerse y cumplir su palabra, ya que sólo a los señores les está permitido hacer verdaderas promesas y cumplirlas.

Pronto, esta dinámica libre se difuminara en el horizonte del advenimiento del cristianismo y su edificio moral con cimientos en la tradición judía. La moral está ligada a la justicia. En este caso, la moral de esclavos es esencialmente normativa, es decir, su interés está puesto más en establecer normas colectivas e imponerlas al pueblo que dejar la responsabilidad de su creación a cada individuo particular según su escala de valores. Estas normas impositivas como se ha dicho, orientaran la acción colectiva y, además de fomentar la decadencia cultural frenando el desarrollo de hombres elevados, estarán legitimadas -a priori- por Dios. La "justicia" que en este caso se identificará casi totalmente con el ordenamiento jurídico vigente, se convertirá en una expresión y en una herramienta más de estas intenciones decadentes. La consecuencia de esta perspectiva, será una dura inmovilidad y fijeza de prescripciones degeneradoras de la vida.

Como se dijo, de los valores morales que defiende el cristianismo, se extraen las características que tendrá la justicia. El hombre pasará a cargar sobre sus espaldas el peso de la culpabilidad mediante la introyección de la culpa y consecuentemente el castigo será parte fundamental del ejercicio de la justicia. En tanto que el hombre es "libre" de actuar de tal o cual manera, de decidir sobre su accionar, de manejar sus intenciones, en tanto que cometa una violación a las normas de la sociedad, éste será "merecedor" del castigo.

Pero, la justicia en la época judeo-cristiana como bien se ha dicho, brota del resentimiento y el ansia de venganza ${ }^{194}$. Por su vicio inicial, no buscará la objetividad

\footnotetext{
${ }^{193}$ Ibíd. p. 92.

194 "Entre ellos hay a montones los vengativos disfrazados de jueces, que constantemente llevan en su boca la palabra 'justicia' como una baba venenosa, que tienen siempre los labios
} 
en sus determinaciones ni la verdad misma, sino que privilegiara el punto de vista del perjudicado. Aquí es importante señalar que los eternos "perjudicados" son los débiles y los "iguales", en tanto que los "agresores" serán los fuertes, los guerreros, los aristócratas, los que planteen la "diferencia". Por lo cual, se establece que lo justo es lo débil ${ }^{195}$, y lo injusto lo fuerte, y esto, constituye el punto más fuerte del desatino cristiano ya que "en sí, ofender, violentar, despojar, aniquilar no pueden ser naturalmente 'injustos desde el momento en que la vida actúa esencialmente, es decir, en sus funciones básicas, ofendiendo, violando, despojando, aniquilando, y no se la puede pensar en absoluto sin ese carácter" ${ }^{196}$.

\section{CAPÍTULO SEGUNDO: “Ideas nietzscheanas sobre el período extramoral y su concepción de justicia"}

\subsection{Caracterización de la moral superior}

\subsubsection{Nihilismo como transición}

Al nihilismo se lo puede definir como un estado psicológico o estado general, en el cual falta el fin, el sentido, ya que se ha producido una desvalorización de valores supremos, por acción de un debilitamiento o eliminación total de una fuerza que lo mantenía unido. El concepto de nihilismo puede ser pertinentemente hermanado con el de "decadencia" entendida ésta como "disgregación". Este estado es percibido por Nietzsche como un síntoma de la época en la que se encontraba ${ }^{197}$.

fruncidos y están siempre dispuestos a escupir a todo aquello que no tenga una mirada descontenta y que avance con buen ánimo por su camino". Ibíd. p. 159.

195 "Ahora han arrendado la virtud en exclusiva para ellos, esos débiles y enfermos incurables, no hay duda: 'sólo nosotros somos los buenos, los justos, dicen, sólo nosotros somos los homines bonae voluntatis [hombres de buena voluntad]" Ibídem.

${ }^{196}$ Ibíd. p. 98.

${ }^{197}$ Cfr. VOLPI, Franco. El nihilismo. Biblios. Madrid, 2005. p. 59. 
Para Nietzsche es Platón quien siembra la primera semilla de nihilismo con su doctrina de los dos mundos, es decir, la idea de que existe una realidad absoluta "en sí" perfecta, eterna, inmutable que se encuentra no en este mundo, sino en otro, y resulta ser más verdadera. En el mundo Inteligible descansan los valores objetivos de la "Verdad" y el "Bien". Seguidamente es el cristianismo el que retoma esta idea y concentra la realidad absoluta en la figura de Dios, a la que le opone el mundo de las cosas naturales, y en la medida en que, según Nietzsche, dicho mundo "superior" es una pura nada, la cultura cristiana, y en definitiva toda la cultura occidental, es nihilista pues dirige toda su pasión y esperanzas a algo inexistente (Dios, el Mundo Ideal y Racional de los filósofos) despreciando de modo indirecto la única realidad existente, la realidad del mundo que se ofrece a los sentidos, la realidad de la vida.

Del desprecio por este mundo sensible, se sigue un desprecio por aquella parte nuestra que pertenece a este mundo y por ende comparte sus características: nuestro cuerpo, es por ello que Nietzsche califica esta religión como "antinatural". Presenta leyes que van en contra de las tendencias primordiales de la vida, es una moral de resentimiento contra los instintos y el mundo biológico y natural, como se ve en se ve reflejado en la mayoría de los valores que enaltece, como ser la abstinencia sexual, el ayuno, la mesura, el control total sobre los instintos y la hegemonía de la razón. Tras un prolongado predominio, estos valores acaban por "enfermar" al cuerpo.

Pero no solo estas valoraciones enferman el cuerpo sino también, hablando de modo impropio la "psiquis". El cristianismo como se ha establecido en el anterior capítulo, instaura la idea de culpabilidad y la de libertad y con estas la de pecado ${ }^{198}$. La idea de pecado es una de las ideas más enfermizas inventadas por la cultura

\footnotetext{
198 "en el que a partir de ahora la mala conciencia de tal modo se asienta, corroe, se extiende y crece (...) que junto con la inextinguibilidad de la culpa se acaba por concebir también la inextinguibilidad de la expiación, el pensamiento de su impagabilidad (...) al final, se vuelve incluso contra el 'acreedor', ya se piense aquí en la causa prima del hombre, en el comienzo del género humano, en el progenitor de éste,(...) o en la naturaleza (...) o en la existencia en general, que queda como no-valiosa en sí (alejamiento nihilista de la existencia, deseo de la nada o deseo de su 'opuesto', de ser-otro, budismo y similares)" NIETZSCHE, Friedrich. La genealogía de la moral. Op. Cit., p. 113.
} 
occidental: con ella el sujeto sufre y se autoflagela a partir de una construcción ficticia, el "Dios juez" al que rendir cuentas por nuestra conducta, la cual es, a partir de aquí, libre. El cristianismo (y todo el moralismo occidental) tiene necesidad de la noción de libertad pues para poder hacer culpables a las personas es necesario antes hacerlas responsables de sus acciones. Ante este Dios el cristiano se siente culpable, observado, valorado e incluso espera de él un castigo.

Sumado a esta actitud antinatural mencionada, a defensa de la igualdad, en el contexto del auge del sistema democrático, en tanto que violenta una de las características principales de la dinámica de la vida, la cual es el ejercicio de la jerarquía y la diferencia, potenciará los efectos negativos en la humanidad resumidos por Nietzsche en este fragmento:

Pues así están las cosas: el empequeñecimiento y la nivelación del hombre europeo encierran nuestro máximo peligro, ya que esa visión cansa... Hoy no vemos nada que aspire a ser más grande, barruntamos que descendemos cada vez más abajo, más abajo, hacia algo más débil, más manso, más prudente, más plácido, más mediocre, más indiferente, más chino, más cristiano -el hombre, no hay duda, se vuelve cada vez 'mejor'... Justo en esto reside la fatalidad de Europa perder el miedo al hombre hemos perdido también el amor a él, el respeto a él, la esperanza en él, más aún, la voluntad de él. Actualmente la visión del hombre cansa - ¿qué es hoy el nihilismo si no es eso?... Estamos cansados del hombre ${ }^{199}$.

Nietzsche describe aquí al hombre devenido camello (una de las tres transformaciones del espíritu que grafica en Así habló Zaratustra). Camello, es aquel hombre que acepta su pesada carga con resignación, porque se ha vuelto manso, así obedece al "gran dragón" que le arroja su carga: "itú debes!".

${ }^{199}$ Ibíd. p. 58. 
Producto de este extrañamiento del hombre con el hombre, de esta pérdida de relación consigo mismo, es la pérdida de relación con Dios. "Dios ha muerto" significa que el hombre ya no posee fuerzas para sostener su fe, por eso él mismo ha ejecutado el asesinato. “¿A dónde ha ido Dios?, gritó, ‘iyo os lo voy a decir! ¡Nosotros lo hemos matado, vosotros y yo! ¡Todos nosotros somos sus asesinos! ¿Pero cómo hemos hecho esto?" ${ }^{200}$.

El horror que experimenta el hombre frenético ante este asesinato responde a la función que la idea de Dios poseía anteriormente: Dios era la fuerza trascendente que vinculaba a la vez que otorgaba sentido y orden. Al perecer Dios, perece con él el fundamento de la Verdad, del Bien: no hay objetividad ni valores supremos sostenibles a partir de ahora.

El nihilista pasivo no cree ya en la totalidad de los valores anteriores unificados gracias a la figura de Dios puesto que su existencia ha perdido realidad. Esta fase de nihilismo se caracteriza por la desidia, apatía, la inacción, la renuncia al deseo un "ocaso y decadencia del poder del espíritu". En este momento crítico encontramos el nihilismo en la desesperación de los que consideran que nada tiene sentido ni valor por no existir aquello que debería ser el fundamento de todo sentido y valor.

Sólo el nihilismo activo logrará destruir completamente los viejos valores en tanto que les quitará el lugar suprasensible en el que se ubicaban y además destruirá la diferencia platónica entre mundo aparente y verdadero. Y aquí una aclaración pertinente: "Abolir el "mundo aparente" significa, más bien, eliminar el modo como lo sensible es visto desde la perspectiva del platonismo esto es, quitarle el carácter de apariencia." ${ }^{201}$.El nihilismo activo pretende restablecer la relación del hombre con lo sensible, en general "hacer posible la nueva posición de valores, basada sobre el

\footnotetext{
${ }^{200}$ NIETZSCHE, Friedrich. La ciencia jovial. Op. Cit. p.115.

201 VOLPI, Franco. El nihilismo. Op. Cit. p. 63.
} 
reconocimiento de la voluntad de poder como carácter fundamental de todo lo que existe" $^{\prime 202}$.

\subsubsection{Espíritu libre y la apertura de nuevos horizontes de pensamiento}

En el prólogo de la obra Humano demasiado humano Nietzsche menciona que el espíritu libre, para llegar a adoptar las características que le convienen, ha debido pasar por un episodio de "desasimiento" que lo ha hecho superar su condición gregaria $^{203}$. Nos tomamos la libertad de interpretar este episodio como la experiencia del nihilismo, de la decadencia de sus antiguas ataduras ${ }^{204}$. La particularidad sería aquí que este hombre de espíritu libre no se paraliza en la experiencia misma de negatividad y desprecio de todo lo antiguo, sino que con esta primera ráfaga de "voluntad de autodeterminación, de autovaloración, esta voluntad de libre albedrío" 205 , voluntad de pronunciar un tajante "iyo quiero!", sale a la búsqueda de nuevos horizontes movido por la curiosidad. Así lo expresa Nietzsche en otra obra:

Ese hombre del futuro, que nos liberará del ideal existente hasta ahora y asimismo de lo que tuvo que nacer de él, de la gran náusea, de la voluntad de la nada, del nihilismo, ese toque de campana del mediodía y de la gran decisión, que de nuevo libera la voluntad, que devuelve a la tierra su meta y al hombre

\footnotetext{
${ }^{202}$ Ibíd. p. 65.

203 “Cabe presumir que un espíritu en el que el tipo 'espíritu libre ha un día de madurar y llegar a sazón hasta la perfección haya tenido su episodio decisivo en un gran desasimiento y que antes no haya sido más que un espíritu atado y que parecía encadenado para siempre a su rincón y a su columna" NIETZSCHE, Friedrich. Humano, demasiado humano. Un libro para espíritus libres. Primer volumen. Op. Cit., p. 37.

204 “¿Qué es lo que ata más firmemente? ¿Cuáles son las cuerdas casi irrompibles? Entre hombres de una clase elevada y selecta los deberes serán ese respeto propio de la juventud, respeto y delicadeza ante todo lo de antiguo venerado y digno, esa gratitud hacia el suelo en que crecieron, hacia la mano que les guio, hacia el santuario en que aprendieron a orar" Ibídem.

${ }^{205}$ Ibíd. p. 38.
} 
su esperanza, ese anticristo y antinihilista, ese vencedor de Dios y de la nada - alguna vez tiene que llegar ${ }^{206}$.

El espíritu libre, revuelve lo que encuentra oculto. "Con malévola risa da vuelta a lo que encuentra oculto, tapado por cualquier pudor: trata de ver el aspecto de las cosas cuando se las invierte." ${ }^{207}$. Pero lo que más le importa, aquello que despierta en grado sumo su curiosidad son las preguntas más peligrosas: “¿¿No es posible subvertir todos los valores?, ¿y es el bien acaso el mal?, ¿y Dios sólo una invención y sutileza del diablo? ¿Es todo acaso en definitiva falso? ${ }^{\prime \prime 2}{ }^{208}$.

Una vez que el espíritu libre haya pasado por un periodo de "enfermedad" caracterizado por la soledad, y la falta de un piso seguro, un cúmulo estable de verdades, adviene la "gran salud" y se deja ver aquello que le es realmente propio: un autodominio, una "disciplina del corazón que le permite el acceso a muchos y contrapuestos modos de pensar", un "exceso de fuerzas plásticas, curativas, reproductoras y restauradoras" ${ }^{209}$ que le permiten vivir en los límites y en el vértigo de la aventura del libre pensamiento.

Más avanzados en Humano demasiado humano, Nietzsche habilitará a semejar el origen del genio con el del libre pensador. De esta semejanza, extraemos la característica principal del genio: la originalidad que le permite transitar nuevos caminos que los marcados por la tradición. Aquí reside la disruptividad del genioespíritu libre-librepensador. Más, ¿cuáles serán estos nuevos caminos por los que su libertad de pensamiento y originalidad lo conducirá a transitar? Inicialmente, unos antagónicos al que habitaba el espíritu gregario.

\footnotetext{
${ }^{206}$ NIETZSCHE, Friedrich. La genealogía de la moral. Op. Cit., pp. 123-124.

207 NIETZSCHE, Friedrich. Humano, demasiado humano. Un libro para espíritus libres. Primer volumen. Op. Cit., p. 37.

${ }^{208}$ Ibídem.

${ }^{209}$ Ibíd. p. 38.
} 
Uno de los problemas que el espíritu libre identifica es el de la jerarquía. Antes, denunciada como injusticia por espíritus incapaces de superación y sedientos por ello de nivelación mediocre ${ }^{210}$. El espíritu libre observará la necesaria revalorización del ejercicio de la distancia, entendiendo que es parte esencial de la dinámica de la vida.

El otro elemento que el espíritu libre estará capacitado para divisar, responde a la nueva visión que tendrá Nietzsche sobre la forma de conocer e interpretar del hombre, el perspectivismo. El cual supone la aceptación de influencias diversas en la construcción del conocimiento y la percepción ${ }^{211}$.

\subsubsection{El superhombre y la autosuperación de la moral}

El espíritu libre abre la mirada, ilumina problemas que antes no se concebían, y así destruye las últimas ráfagas de vida de la tradición. Pero el espíritu libre todavía es león y no niño.

Pero decidme hermanos míos, ¿que es capaz de hacer el niño que ni siquiera el león ha podido hacer? ¿Por qué el león rapaz tiene que convertirse todavía en niño? Inocencia es el niño, y olvido, un nuevo comienzo, un juego, una rueda que se mueve por sí misma, un primer movimiento, un santo decir sí.

\footnotetext{
210 "Puesto que es del problema de la jerarquía del que nosotros espíritus libres podemos decir que es nuestro problema, sólo ahora, en el mediodía de nuestra vida, comprendemos qué preparativos, rodeos, pruebas, tentativas, disfraces había menester el problema antes de que éste pudiera planteársenos" NIETZSCHE, Friedrich. Así habló Zaratustra. Op. Cit. p. 102.

211 "Debías aprender a captar lo perspectivista de toda valoración; la deformación, la distorsión y la aparente teleología de los horizontes y todo lo que pertenece a lo perspectivista" NIETZSCHE, Friedrich. La genealogía de la moral. Op. Cit., p. 122.
} 
Sí hermanos míos, para el juego del crear se precisa en santo decir sí: el espíritu quiere ahora su voluntad, el retirado del mundo conquista ahora su mundo. ${ }^{212}$

He aquí la diferencia, el espíritu libre en tanto león solo utiliza su fuerza disruptiva para disolver los últimos vestigios de valores viejos y abrir perspectivas, en tanto que el superhombre es el único capaz de alcanzar la última transformación y siendo niño es el único que puede crear nuevos valores. El espíritu libre divisa en el horizonte el problema de la perspectiva y la jerarquía, pero es el superhombre el que posee características de niño: que lo capacitan para dar respuesta a estos problemas creando una nueva tabla de valores.

La cuestión planteada como el primer problema a resolver en el presente trabajo, necesita ser zanjada aquí para poder continuar. Pareciera ser que la radicalidad del ataque a la moral no nos permitiera a partir de aquí volver a hablar en ningún sentido de cualquier tipo de moral $^{213}$, aunque también Nietzsche permite interpretar que el ataque se encuentra dirigido solo a la moral de esclavos ${ }^{214}$. En el caso de que la "destrucción" fuera radical, deberíamos optar por englobar al conjunto de valores creados por el superhombre en el concepto de "ethos". Pero, en el caso de que consideremos que el ataque es parcial, podemos hablar de una moral superior.

\footnotetext{
${ }^{212}$ NIETZSCHE, Friedrich. Así habló Zaratustra. Op. Cit. p. 102.

213 “La superación de la moral, y en cierto sentido incluso la autosuperación de la moral: acaso sea éste el nombre para designar esa labor prolongada y secreta que ha quedado reservada a las más sutiles y honestas, también a las más maliciosas de las conciencias de hoy, por ser éstas vivientes piedras de toque del alma". NIETZSCHE, Friedrich. Más allá del bien y el mal. Preludio de una filosofía del futuro. Op. Cit. p. 62.

214 "En el fondo, la palabra inmoralista contiene para mí dos negaciones. El primer "no" lo remito al hecho siguiente: yo soy todo lo contrario, por una parte, de un tipo de hombre que habría sido considerado hasta el presente como el tipo superior; el hombre bueno, benévolo, caritativo; y el segundo "no": a un género de moral que ha adquirido importancia, que ha llegado a ser poderosa como moral en sí, la moral de la décadence, para expresarme de una manera más precisa, la moral cristiana." NIETZSCHE, Friedrich. Ecce Homo. Trad. Alicia Varela. Gradifco, Buenos Aires, 2007.
} 
Pues bien, se adoptará aquí una idea conciliadora entre ambas posiciones. La destrucción si bien es profunda, sigue habilitando a manejarnos en el terreno de conceptos morales, tal vez por intenciones estratégicas de inteligibilidad del problema por parte de Nietzsche. La particularidad, resulta ser que si bien se manejara con conceptos tradicionales, planteara un tipo de moral diametralmente superadora de la anterior. A continuación se desarrollará la propuesta lo más completa posible y se verá justificada esta posición adoptada.

El superhombre comprenderá que tanto él como el mundo en general, está constituido por una voluntad, la voluntad de poder. Esta voluntad, no es aquella abstracta e indiferente que piensan los psicólogos de la época, ni es aquella "voluntad de verdad" de la que habla el filósofo teórico, tampoco coincide con la voluntad de su maestro Schopenhauer, la voluntad de vida, porque más bien la vida es voluntad de poder.
“En todos los lugares donde encontré seres vivos, encontré voluntad de poder, e incluso en la voluntad del que sirve encontré voluntad de ser señor. (...)
Y este misterio me ha confiado la vida misma. Mira, dijo, yo soy lo que tiene que superarse siempre a sí mismo."215

Es el principio básico, la fuerza primordial de la realidad a partir del cual se desarrollan todos los seres. En la Genealogía de la moral, Nietzsche les responde a aquellos que sostienen que la dinámica de los organismos y de la vida en general es "adaptación”: “(..) Con ello se desconoce la esencia de la vida, su voluntad de poder; con ello se pasa por alto la supremacía de principio que poseen las fuerzas espontáneas, agresivas, invasoras, creadoras de nuevas interpretaciones, de nuevas

\footnotetext{
${ }^{215}$ NIETZSCHE, Friedrich. Así habló Zaratustra. Op. Cit. p. 176.
} 
direcciones y formas. ${ }^{216}$ Primero, actúa la voluntad de poder creando e imponiendo, y luego recién sobreviene la adaptación.

Junto con la noción de voluntad de poder, viene dada la de "eterno retorno". En La voluntad de poder ${ }^{217}$ Nietzsche argumentando en favor de la idea del eterno retorno plantea que si este universo se dirigiera hacia un estado acabado o final, éste debería haberse alcanzado. Pero como claramente ello no sucedió, cabe afirmar que no hay otro universo o mundo posible al modo platónico o cristiano. Es más, este mismo mundo, se volverá a repetir tal cual se desarrolla. De aquí la consigna resulta evidente: hay que permanecer "fieles a la tierra", a este mundo, a esta vida y a nuestro cuerpo. Y más, actuar tal que deseemos que lo que hagamos se repita eternamente.

El desenvolvimiento libre de estas fuerzas, y su afirmación por el superhombre constituirá el "fundamento" de todos los valores, que a partir de aquí englobe la "moral superior". Como se observa, que el valor de todos los valores dependa de fuerzas fluctuantes y dinámicas, implicara que esta moral no pueda establecer parámetros valorativos eternos e inmutables, como la anterior moral de esclavos.

Una de las cosas que valorará esta moral es, nuevamente, el cuerpo y con él su "salud". Se había dicho que lo que la moral de esclavos estimaba partía de aquello que "enfermaba" al cuerpo, entre otras cosas, el resentimiento, la venganza que no se puede descargar, los instintos negados y descargados hacia dentro en forma de culpa.

Pues bien, esta moral reivindicará el libre fluir de estas fuerzas en todos los ámbitos de acción del hombre. Por ello valorará la acción de tipo "activa". Esta fuerza, que primará en la acción del hombre superior, consiste por un lado en ser autoafirmación en tanto que parte y se descarga desde el mismo hombre hacia afuera (a diferencia de aquella "reactiva" que parte desde otro para negar). Por otro lado,

\footnotetext{
${ }^{216}$ NIETZSCHE, Friedrich. La genealogía de la moral. Op. Cit. p. 102.

${ }^{217}$ NIETZSCHE, Friedrich. La voluntad de poder. Madrid, Edaf, 2000.
} 
esta fuerza se descargará imponiendo y dominando. En general de modo violento y cruel, lo cual no será menospreciado por Nietzsche ya que la capacidad de hacerlo implicara una fuerza y vigorosidad también signo de salud.

En tanto que valorará la autoafirmación, también rechazará la igualdad entre los hombres. Sería inverosímil creer que el despliegue de nuestras fuerzas se desarrolla en todos de la misma manera y quiere lo mismo. Por ello celebrará y alentará la jerarquía, tanto al interior de cada hombre (en cada uno se librará una lucha entre sus instintos y uno será el que prevalecerá) como entre los hombres (los hombres no son iguales, se diferencian por su mayor o menor grandeza) ${ }^{218}$. Y esto porque como se dijo, la vida misma posee una tendencia a ascender jerárquicamente, creando productos cada vez más poderosos. Y esta tendencia supone la lucha y antagonismo constante entre contrarios.

Como se dijo también, la idea de culpabilidad será eliminada. Ya que el superhombre hará honor a la irracionalidad que caracteriza a voluntad de poder encarnando una inocencia de niño, ubicándose más allá del bien y del mal (del mismo modo que los niños en tanto que no han adquirido todavía las nociones del adulto sobre lo bueno y lo malo).

\subsection{Concepción de justicia en el horizonte de una moral superior}

\footnotetext{
${ }^{218}$ Toda elevación del tipo 'hombre' ha sido hasta ahora obra de una sociedad aristocrática (...) es ésa una sociedad que cree en una larga escala de jerarquía y de diferencia de valor entre un hombre y otro hombre(...). Sin ese pathos de la distancia que surge de la inveterada diferencia entre los estamentos, de la permanente mirada a lo lejos y hacia abajo dirigida por la clase dominante sobre los súbditos e instrumentos, y de su ejercitación, asimismo permanente, en el obedecer y el mandar, (...) no podría surgir tampoco en modo alguno aquel otro pathos misterioso, aquel deseo de ampliar constantemente la distancia dentro del alma misma, la elaboración de estados siempre más elevados (...) en una palabra, justamente la elevación del tipo 'hombre', la continua 'auto-superación del hombre' para emplear en sentido sobremoral una fórmula moral. NIETZSCHE, Friedrich. Más allá del bien y el mal. Preludio de una filosofía del futuro. Op.Cit. p. 232.
} 
Siguiendo la línea de interpretación de Ricardo Marquisio ${ }^{219}$ para el desarrollo de este apartado final, sostenemos que el punto focal de la concepción de justicia que se desarrolle en el seno de la moral superior, estará puesto sobre el mismo hombre ejecutor de ella. Ya que, una vez anulado el concepto de "verdad" eterna, inmutable, a la vez que el de "mentira", no queda más valor veritativo y fuente de legitimidad que el buen juicio del justo, afirmador de la voluntad de poder.

“La justicia así entendida es una virtud. Es decir, una propiedad disposicional humana [del justo] desarrollada por medio del ejercicio de la acción virtuosa (...). Lo esencial en una ética que tiene a las virtudes como su centro es su naturaleza “performativa" ${ }^{220}$. Es decir que lo que más importará será la acción llevada a cabo antes que la norma que pueda establecer el justo.

Es por esto que conviene, aun habiendo establecido como característica principal del hombre superior su afirmación de la voluntad de poder, recoger la descripción que Nietzsche realiza en el segundo tratado de la Genealogía de la moral:

\section{“(...) [Como un fruto maduro de un largo proceso, encontraremos]} al individuo soberano, al individuo igual tan sólo a sí mismo(...) encontraremos al hombre de la duradera voluntad propia, independiente, al que le es lícito hacer promesas (...)¿cómo no iba a conocer la superioridad que con esto tiene sobre todo aquello a lo que no le es lícito hacer promesas ni responder de sí, (...) y cómo, en este dominio de sí mismo, [no iba a saber que] le está dado necesariamente el dominio de las circunstancias, de la naturaleza y de todas las criaturas menos fiables, más cortas de voluntad?"221

\footnotetext{
${ }^{219}$ MARQUISIO, RICARDO. Nietzsche y la justicia sin moral. Disponible en: http://www.actio.fhuce.edu.uy/Textos/9/Marquisio9.pdf

${ }^{220}$ Ibíd. p. 61.

${ }^{221}$ NIETZSCHE, Friedrich. La genealogía de la moral. Op. Cit. p. 78.
} 
Nietzsche suma aquí una serie de características fundamentales: un profundo auto conocimiento y una conciencia de libertad y responsabilidad que juntos constituyen una voluntad vigorosa, aquella que le da legitimidad para hacer promesas.

Este es el hombre activo, el que gracias a un contundente dominio de sí, y también por ser el más "fuerte, el más valeroso, el más noble, ha poseído también un ojo más libre, una conciencia más buena" ${ }^{222}$, esto lo lleva a decir a Nietzsche que también “está siempre cien pasos más cerca de la justicia que el hombre reactivo" ${ }^{223}$.

Su objetividad será destacable, y lo conducirá a comportarse equilibradamente incluso con aquél que le ha perjudicado ${ }^{224}$. Y, además, a someterse de igual modo que somete a otros, a las leyes y acuerdos que él mismo ha imponga. Su palabra es valiosa y la respalda una fuerza que lo capacita a mantenerla.

Este hombre superior, "poseedor de una voluntad duradera e inquebrantable" tendrá fijada su "medida de valor" según esta capacidad de mantener la palabra, en tanto que: valorara a aquellos iguales a él en fuerza, ya que son veraces y fiables en el cumplimiento de sus acuerdos, y (...) "con igual necesidad tendrá preparado su puntapié para los flacos galgos que hacen promesas sin que les sea lícito, y su estaca para el mentiroso que quebranta su palabra ya en el mismo momento en que aún la tiene en la boca" ${ }^{225}$.

De aquí resulta que el derecho ha sido por necesidad, creación del justo, para imponer "freno y medida al desbordamiento del pathos reactivo y obligar por la

\footnotetext{
${ }^{222}$ NIETZSCHE, Friedrich. La genealogía de la moral. Op. Cit. p. 97.

${ }^{223}$ Ibíd. p. 96.

224 "Cuando de verdad ocurre que el hombre justo es justo incluso con quien le ha perjudicado (y no sólo frío, mesurado, extraño, indiferente: ser-justo es siempre un comportamiento positivo), cuando la elevada, clara, profunda y suave objetividad del ojo justo, del ojo juzgador, no se turba ni siquiera ante el asalto de ofensas, burlas, imputaciones personales, esto constituye una obra de perfección y de suprema maestría en la tierra" Ibídem.

${ }^{225}$ Ibíd. p. 78.
} 
violencia a un compromiso" 226 . El justo, se ve obligado a imponer acuerdos y leyes a nivel jurídico y a nivel moral a modo de prescripciones y restricciones.

Aunque aquel sabrá cuán dinámicas y transitorias serán estas en el marco de un mundo hecho de un puro devenir" 227 . Dice Nietzsche que "a las situaciones de derecho no les es lícito ser nunca más que situaciones de excepción, que constituyen restricciones parciales de la auténtica voluntad de vida, la cual tiende hacia el poder" $^{228}$.

El problema que se dibuja es determinar cuál es el criterio con el cual evaluar las prescripciones que determina el justo. Pues bien, algo de ello se ha dicho. Nietzsche establece que la legitimidad de estas restricciones que pueden imponerse al comportamiento de los hombres sólo puede surgir de "[su subordinación] a finalidad global de aquella voluntad como medios particulares: es decir, como medios para crear unidades mayores de poder" 229 y Marquisio agrega "contribuirán a lo sumo a instaurar una determinada constelación de poder hasta el arribo de otra, a la que la primera será subordinada o incorporada"230. En definitiva, sólo resultarán justas aquellas "restricciones" que contribuyan a la expansión de la vida.

Se manifiesta entonces con más claridad la diferencia tajante entre un tipo de justicia producto de la moral de esclavos y aquella que florece en los prados fértiles de la moral superior. Aquí ya no son los débiles quienes imponen su criterio enfermo, sesgado y homogeneizador. Sino los hombres superiores, dotados de una vista más amplia debido a su fortaleza de carácter quienes establecen los parámetros de lo justo

\footnotetext{
${ }^{226}$ Ibíd. p. 113.

227 “La voluntad de justicia, es, en esencia, la de acción e imposición, para construir al mismo tiempo que se destruye" MARQUISIO, RICARDO. Nietzsche y la justicia sin moral. Op. Cit. p. 63.

${ }^{228}$ NIETZSCHE, Friedrich. La genealogía de la moral. Op. Cit. p. 98.

${ }^{229}$ Ibídem.

${ }^{230}$ MARQUISIO, RICARDO. Nietzsche y la justicia sin moral. Op. Cit. p. 64.
} 
e injusto honrando la vida ${ }^{231}$ (mediante la revalorización del comportamiento guerrero: imposición, dominio, violencia, crueldad) y a su misma jerarquía en tanto que reconocen a sus iguales y desprecian y obligan a los inferiores. La justicia, será justicia al servicio de los que tienen la capacidad de desplegar la libre dinámica de la voluntad de poder mediante la creación de leyes y acuerdos.

Marquisio plantea como hipótesis conveniente de recuperar aquí, que la supervivencia de esta justicia en el marco de la sociedad superior depende de "su transformación [desde valor moral a] valor estético"232. En tanto que establecimos precedentemente el hecho de que esta justicia va a depender enteramente del justo y su afirmación de la voluntad de poder, lo que plantea Marquisio es que en una "segunda etapa" el hombre justo no deberá ya ejercer con primacía tareas de un "agente moral" imponiendo normas prescriptivas (aunque esto sea parte ineludible en cierta medida) sino que estará mayormente "caracterizado por su actitud "dionisiaca" ante la vida, que implica una voluntad de afirmación incondicional de ésta, y cuya acción ha de ser juzgada exclusivamente desde su condición creadora y no de acuerdo con criterios morales" ${ }^{233}$.

\section{Conclusión}

Tras haber realizado el trabajo de investigación e interpretación correspondiente, se corrobora satisfactoriamente la hipótesis y se está en condiciones de ampliar su alcance.

\footnotetext{
${ }^{231}$ Hablar en sí de lo justo y lo injusto es algo que carece de todo sentido; en sí, ofender, violentar, despojar, aniquilar no pueden ser naturalmente 'injustos desde el momento en que la vida actúa esencialmente, es decir, en sus funciones básicas, ofendiendo, violando, despojando, aniquilando, y no se la puede pensar en absoluto sin ese carácter. NIETZSCHE, Friedrich. La genealogía de la moral. Op. Cit. p. 95.

${ }^{232}$ MARQUISIO, RICARDO. Nietzsche y la justicia sin moral. Op. Cit. p. 63.

${ }^{233}$ Ibídem.
} 
Nietzsche aun habiendo ejecutado una crítica exhaustiva y concluyente a todo aquello que compone la moral de esclavos, y a ciertos tipos de moral por fuera de este, al presentar su propuesta renovadora y superadora continua haciendo uso de términos y estructuras conceptuales de una ética tradicional. Arriesgamos la idea de que esto no constituye una mera contradicción en el pensamiento del filósofo sino una estrategia para asegurarse la comprensión de sus lectores, por más reiteradas veces que pueda manifestar su aparente desdén por ser entendido por todos.

La particularidad, resulta ser que, su propuesta plantea una apertura y dinamismo tales que nos previene de confundirla con cualquier otra perteneciente a etapas de influencia judeo-cristiana.

Nietzsche circunscribe sus esperanzas en el advenimiento de un nuevo mundo, de una nueva era, en el que la afirmación de la voluntad de poder se convierta en guía y parámetro en todo ámbito de la vida. Lo cual implica decir que todos los esfuerzos deben estar circunscritos a la búsqueda de la expansión de la vida mediante el libre fluir de nuestras fuerzas, lo cual implica a la vez la revalorización de la lucha, el ansia de dominio y explotación, la determinación de jerarquías. La diferencia con la moral de esclavos es contundente. Mientras una promueve la diferencia entre hombres superiores e inferiores, la otra aboga por una igualación en la mediocridad, mientras una celebra la lucha y el regocijo en el placer de la crueldad, la otra obliga a hermandad y concordia entre los hombres, mientras una promueve el libre fluir de todos los instintos, la otra lo reprime, en general, en tanto que una ama la vida, la otra la odia.

Aunque lo mejor que podría resumir aquí sus diferencias es el hecho de que mientras la moral superior se construye a partir de sentimientos activos, propios de un hombre fuerte, libre y poderoso, la otra parte de hombres vengativos e impotentes.

Por estas características, le corresponde al hombre superior impartir su juicio y legislar con objetividad, más bien, crear el sentido de lo que se entenderá a partir de aquí como justo e injusto. Lo cual, como se ha adelantado, tiene como parámetro la expansión vital y la creación de nuevos y superiores tipos de hombres. 